\title{
Development and Application of a Thermal Comfort Model in Buildings
}

\author{
Andrés Vilaboa Díaz ${ }^{*}$ and Pastora M. Bello Bugallo D \\ Department of Chemical Engineering, School of Engineering, Universidade de Santiago de Compostela, Avda. Lope Gómez de \\ Marzoa s/n. Campus Vida, 15782 Santiago de Compostela, Spain
}

Received: 11 July 2021 / Received in final form: 30 September 2021 / Accepted: 30 September 2021

\begin{abstract}
Buildings are one of the systems that more energy consumed in the European Union. The study of the thermal envelope is interesting in order to reduce the energy losses. For that, a mathematical model able to predict the system response to external temperature variations is developed. With the mathematical model, different thermal envelope elements of a building based on the lag and the cushioning of the resultant wave can be characterized. In addition, it is important to analyse where the insulation is placed, because when the insulation is outside and the thermal mass is inside, the system produces a response with smooth temperature variations than when the insulation is inside. Therefore, placing the outside insulation generates more steady indoor temperatures, increasing the thermal comfort inside the building. To complete the mathematical model that allows predicting the temperature inside a building taking into account the solar inputs and the thermal inertia of the building. This study will help to establish the optimum design parameters in order to build sustainable and comfortable buildings. Furthermore, it will take one step forward in the construction of nearly Zero-Energy Buildings.
\end{abstract}

\section{Introduction}

Energy is a valuable and indispensable resource for social development. Fossil energy resources are finite and the world reserves decrease, so the energy is becoming a most precious asset for the sustainable development of human activity. The continuous emissions of greenhouse gases (GHG) will cause a greater warming and it will increase the likelihood of serious widespread and irreversible impacts on people and the ecosystems [1].

Buildings are one of the major consumers of primary energy in EU. As can be seen in Figure 1, they are responsible of more than $40 \%$ of European Union final energy consumption (including household, commercial and public services) and $36 \%$ of the total emissions of $\mathrm{CO}_{2}[2]$. The buildings are one of sectors to improve. Among the main efforts is found the renovation of the actual building stock to convert them into buildings with high energy efficiency and decarbonized before 2050 [3].

For increasing energy efficiency in buildings, this study analyses thermal inertia and its implications in the indoor temperature. A good design of the building envelope,

\footnotetext{
* e-mail: andres.vilaboa@rai.usc.es
}

taking into account the thermal inertia of its materials allows us to obtain a more stable temperature inside the buildings and therefore comfort is increased.

Ferrari (2007) defined the thermal inertia of the building as the heat storage capacity in its structure and its performance to slow down heat transmission [5]. The heat accumulation capacity of the building envelope has an impact on the final energy consumption. If two building elements with the same thermal transmittance but different energy accumulation capacity are compared, those elements having the greatest heat capacity produce energy savings in heating and cooling [5-7]. On the other hand, if the thermal inertia are combined with other types of energy saving systems (such as solar shadow device), the energy saving in cooling improves notably. Energy savings in cooling in a building with solar shadow device can be $19 \%$ lower when using walls with high thermal inertia [8].

On the other hand, the ability of energy accumulation not only depends on its heat capacity, but it also affects its density and its thermal conductivity. By increasing density, a heavier structure is obtained and, as a result, the energy storage capacity increases. This structure delays the heat transfer by increasing the gap of the thermal wave. Furthermore, this increased density produces a greater stability of the indoor temperature. In addition, the optimal 


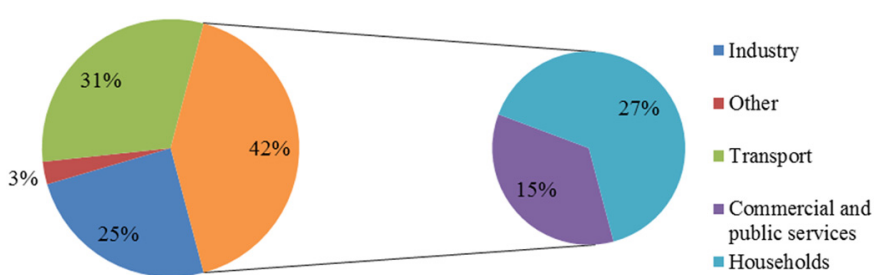

Fig. 1. Final energy consumption in EU by sector in 2017 (Data source: European Environment Agency [4]).

density of the material must be selected according to the type of climate varying between 1.800 and $2.500 \mathrm{~kg} / \mathrm{m}^{3}$ [9]. Finally, the thermal conductivity of the material also influences thermal inertia, since highly conductive materials allow greater heat flow, which facilitates the loss of the energy accumulated in materials. Then, materials with high conductivity cause a minor gap and greater temperature oscillation [10].

Traditional houses, built with materials with high thermal inertia, have an indoor environment more stable than modern houses built with lightweight materials. Specially, in summer and winter, when the outside temperature variation has a value of $25.4^{\circ} \mathrm{C}$ and $23.6^{\circ} \mathrm{C}$, respectively, the decrement factor in buildings with heavier materials has a value about 0.20 [11]. This behaviour is also observed in historical buildings. The stone used in this type of building has a high thermal inertia, which allows maintaining the interior temperature at stable values. In addition, ventilation systems at night, allow to eliminate the heat accumulated by the walls [12].

Knowing the influence of the thermal inertia in the indoor temperature evolution helps to improve climate systems. Thus, the control of this property when designing envelope elements improves building energy efficiency. However, in spite of having a low heat capacity, the use of thermal insulation also has special importance. In fact, the placement of thermal insulation on the outside offers better results than placing it on the inside [13]. Also, the insulation helps to decrease the decrement factor and the increase the lag [14].

There are different methods to analyse the thermal behaviour of a wall, allowing the analysis of different scenarios without the need for experimental data collection. Resolution by electrical network analogy is also widely used in scientific literature, which establishes the analogy between the electric and thermal field. Currently, numerical simulation models are already widely used; they allow evaluating the performance of buildings through the use of commercial software or creation of their own code. This type of simulation software allows to evaluate a wide range of physical phenomena [15].

In this paper, the mathematical model is established using the relationship between electrical and thermal analogy. For the development of the equations, the unidirectional heat flow will be assumed, which will allow to avoid the thermal behaviour of the wall in the face of different disturbances. The model will take into account those areas of the buildings in contact with constant temperatures, the influence of ventilation and internal loads. In addition, the model will allow evaluating the influence of solar radiation.

The thermal capacity of materials seems to be a relevant parameter to analyse for moderate climates and intermediate seasons, where it can work as a stabilizing factor of the thermal dynamics of the whole building system [16].

\section{Objectives}

The main objective of this paper is to develop a model that allows analyzing the indoor temperature in buildings. The model will be developed based on the analogy between the electric and thermal field. The model will allow to obtain the temperature on the inner surface of a wall. Subsequently, an energy balance will be carried out to obtain the temperature inside a building taking into account different variables. To complete the mathematical model, the solar radiation will be added to achieve a mathematical model more complete.

At the same time, the dynamic response of a singlelayer wall is analysed. The system is subjected to a sinusoidal disturbance, and its response on the indoor surface is also analysed. Thus, the response of enclosures having different thermal properties can be compared.

In addition, this paper tries to show the importance of designing various elements of the thermal envelope properly, in order to achieve more stable indoor conditions; as well as the advantages offered by the correct placement of the insulating material in opaque enclosures with the same thermal transmittance.

\section{Methodology}

The development of the mathematical model that allows the prediction of the indoor building temperature depending on the outdoor temperature variations is based on the method of Equivalent Electrical Network. This model uses the analogy between an electric circuit and the heat transfer through a multi-layer wall. It can be an electric circuit consisting of capacitors and resistors to simulate the heat capacity and envelope thermal resistance, respectively.

In this way, the model that allows predicting the behaviour of a monolayer wall will be developed. This model will allow to evaluate the thermal behaviour of different materials and also to evaluate the optimal placement of the thermal insulation. Subsequently, applying an energy balance, a model will be developed to calculate the interior temperature. Finally, the influence of solar radiation through the walls and windows will be included.

\section{Development and presentation of results}

\subsection{Analysis of a single-layer wall}

To develop the model, the analogy between the electric and thermal field in a monolayer wall will be used. The wall is represented (Fig. 2) by a resistor (R) and a capacitor (C) 


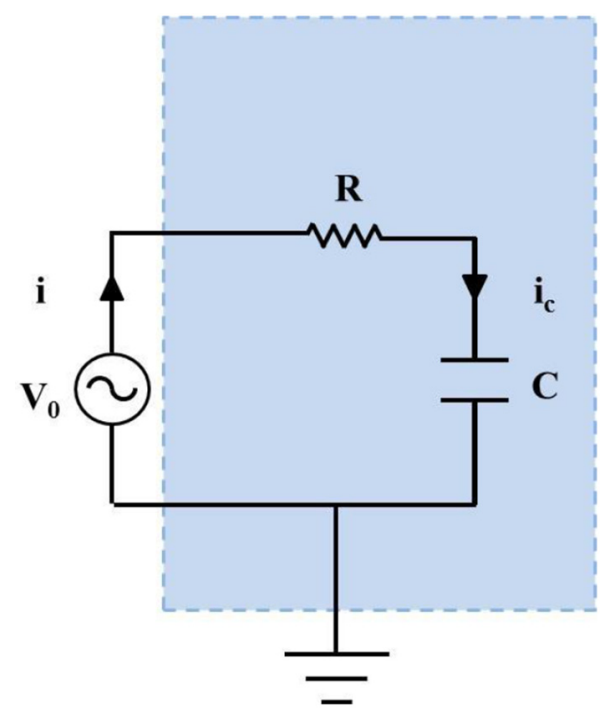

Fig. 2. Representation of a monolayer wall as an electrical circuit.

that represent the thermal resistance and the heat capacity of the wall, respectively. The variation of the external temperature will be represented by the potential difference (V0) and the internal surface temperature by the power difference in the condenser (VC).

The heat flow through the wall is represented by the intensity through the circuit $\left(\mathrm{i}=\mathrm{i}_{\mathrm{c}}\right)$.

$$
i(t)=i_{c}(t)=C \cdot \frac{d V_{c}(t)}{\mathrm{d} t}
$$

The voltage on the capacitor $\left(V_{C}\right)$, which depends on the time, can be calculated using Kirchhoff's law. So, the intensity through the condenser must be equal to the intensity that circulates through the resistance.

$$
V_{0}(t)=i_{r}(t) \cdot R+V_{c}(t)
$$

The intensity flowing through the capacitor $\left(i_{C}\right)$ is equal to that flows through the resistance $\left(i_{r}\right)$. So, combining equations (1) and (2), the following expression is obtained:

$$
V_{0}(t)=i_{c}(t) \cdot R+V_{c}(t)=R \cdot C \cdot \frac{d V_{c}(t)}{\mathrm{d} t}+V_{c}(t)
$$

By using Laplace transforms, this equation can be solved:

$$
\frac{\mathrm{V}_{\mathrm{c}}(\mathrm{s})}{\mathrm{V}_{0}(\mathrm{~s})}=\frac{1}{\mathrm{R} \cdot \mathrm{C} \cdot \mathrm{s}+1}
$$

From equation (4), the relationship between the input voltage and the voltage across the capacitor is obtained. Using the electrical analogy, this expression represents the relationship between the inner surface $\left(T_{\text {sur,in }}\right)$ and external surface $\left(T_{\text {ext }}\right)$.

$$
\frac{\mathrm{T}_{\mathrm{sur}, \mathrm{in}}(\mathrm{s})}{\mathrm{T}_{\text {ext }}(\mathrm{s})}=\frac{1}{\mathrm{R} \cdot \mathrm{C} \cdot \mathrm{s}+1}
$$

where $C$ is the heat capacity of the node $\left(\mathrm{J} / \mathrm{m}^{2} \cdot \mathrm{K}\right) ; R$ is the thermal resistance of the node $\left(\mathrm{m}^{2} \cdot \mathrm{K} / \mathrm{W}\right)$.

By establishing a monolayer wall as a single $\mathrm{RC}$ circuit, inaccurate results can be obtained since the energy accumulation temperature is equal to the temperature of the inner surface. If the wall is divided into a greater number of circuits, it will be possible to obtain a greater precision in the results. In the case of using two nodes to calculate the surface temperature, the equation obtained is the following:

$\frac{V_{c 2}(s)}{V_{0}(s)}=\frac{1}{C_{2} \cdot R_{2} \cdot C_{1} \cdot R_{1} \cdot s^{2}+\left(C_{2} \cdot R_{1}+C_{2} \cdot R_{2}+C_{1} \cdot R_{1}\right) \cdot s+1}$

This transfer function has a higher precision than equation (4). The wall is divided in two sections, so the spatial interval is smaller. Considering two nodes, a system of two equations and two unknowns is obtained.

$$
\left(\begin{array}{l}
V_{0}(s) \\
V_{c 1}(s)
\end{array}\right)=\left(\begin{array}{cc}
1+C_{1} \cdot R_{1} \cdot s & C_{2} \cdot R_{1} \cdot s \\
0 & 1+C_{2} \cdot R_{2} \cdot s
\end{array}\right) \cdot\left(\begin{array}{c}
V_{c 1}(s) \\
V_{c 2}(s)
\end{array}\right)
$$

From the matrix obtained, $n$ nodes can be considered to solve a homogeneous wall, obtaining a system of $n$ equations with $\mathrm{n}$ unknowns.

\section{See equation (8) below.}

with the matrix obtained, the number of calculation nodes is increased and therefore more precise results will be obtained. In this way, the accumulation temperature of the

$$
\left(\begin{array}{l}
\mathrm{V}_{0}(\mathrm{~s}) \\
\mathrm{V}_{\mathrm{c} 1}(\mathrm{~s}) \\
\mathrm{V}_{\mathrm{c} 2}(\mathrm{~s}) \\
\mathrm{V}_{\mathrm{c} 3}(\mathrm{~s}) \\
\vdots \\
\mathrm{V}_{\mathrm{cn}-1}(\mathrm{~s})
\end{array}\right)=\left(\begin{array}{cccccc}
1+\mathrm{C}_{1} \cdot \mathrm{R}_{1} \cdot \mathrm{s} & \mathrm{C}_{2} \cdot \mathrm{R}_{1} \cdot \mathrm{s} & \mathrm{C}_{3} \cdot \mathrm{R}_{1} \cdot \mathrm{s} & \mathrm{C}_{4} \cdot \mathrm{R}_{1} \cdot \mathrm{s} & \cdots & \mathrm{C}_{\mathrm{n}} \cdot \mathrm{R}_{1} \cdot \mathrm{s} \\
0 & 1+\mathrm{C}_{2} \cdot \mathrm{R}_{2} \cdot \mathrm{s} & \mathrm{C}_{3} \cdot \mathrm{R}_{2} \cdot \mathrm{s} & \mathrm{C}_{4} \cdot \mathrm{R}_{2} \cdot \mathrm{s} & \cdots & \mathrm{C}_{\mathrm{n}} \cdot \mathrm{R}_{2} \cdot \mathrm{s} \\
0 & 0 & 1+\mathrm{C}_{3} \cdot \mathrm{R}_{3} \cdot \mathrm{s} & \mathrm{C}_{4} \cdot \mathrm{R}_{3} \cdot \mathrm{s} & \cdots & \mathrm{C}_{\mathrm{n}} \cdot \mathrm{R}_{3} \cdot \mathrm{s} \\
0 & 0 & 0 & 1+\mathrm{C}_{4} \cdot \mathrm{R}_{4} \cdot \mathrm{s} & \cdots & \mathrm{C}_{\mathrm{n}} \cdot \mathrm{R}_{4} \cdot \mathrm{s} \\
\vdots & \vdots & \vdots & \vdots & \vdots & \vdots \\
0 & 0 & 0 & 0 & 0 & 1+\mathrm{C}_{\mathrm{n}} \cdot \mathrm{R}_{\mathrm{n}} \cdot \mathrm{s}
\end{array}\right)\left(\begin{array}{c}
\mathrm{V}_{\mathrm{c} 1}(\mathrm{~s}) \\
\mathrm{V}_{\mathrm{c} 2}(\mathrm{~s}) \\
\mathrm{V}_{\mathrm{c} 3}(\mathrm{~s}) \\
\mathrm{V}_{\mathrm{c} 4}(\mathrm{~s}) \\
\vdots \\
\mathrm{V}_{\mathrm{cn}}(\mathrm{s})
\end{array}\right)
$$


Table 1. Thermal properties of materials used in the simulation (IETCC, 2010).

\begin{tabular}{llllll}
\hline Material & $\begin{array}{l}\text { Heat capacity } \\
(\mathrm{J} / \mathrm{kg} \cdot \mathrm{K})\end{array}$ & $\begin{array}{l}\text { Density } \\
\left(\mathrm{kg} / \mathrm{m}^{3}\right)\end{array}$ & $\begin{array}{l}\text { Conductivity } \\
(\mathrm{W} / \mathrm{m} \cdot \mathrm{K})\end{array}$ & $\begin{array}{l}\text { Thermal mass } \\
\left(\mathrm{J} / \mathrm{m}^{2} \cdot \mathrm{K}\right)\end{array}$ & $\begin{array}{l}\text { Thermal diffusivity } \\
\left(\mathrm{cm}^{2} / \mathrm{s}\right)\end{array}$ \\
\hline Concrete & 1.000 & 2400 & 2.50 & 480.000 & 0.0104 \\
Brick & 850 & 1630 & 0.60 & 277.100 & 0.0043 \\
Granite & 1.000 & 2600 & 2.80 & 520.000 & 0.0108 \\
Wood middleweight & 1.600 & 650 & 0.18 & 208.000 & 0.0017 \\
Insulation & 1.404 & 30 & 0.03 & 8.424 & 0.0076 \\
\hline
\end{tabular}

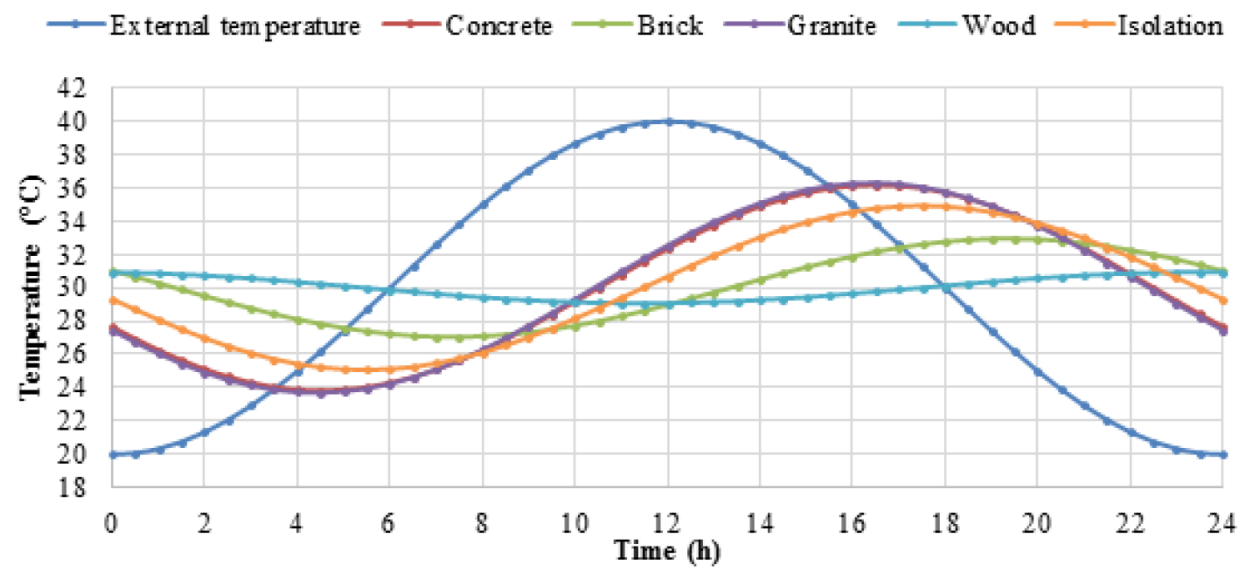

Fig. 3. Representation the response in the inner surface of different materials with a $20 \mathrm{~cm}$ thickness when the system is perturbed from a sine wave.

Table 2. Summary of the results obtained in the simulation for different materials with a $20 \mathrm{~cm}$ thickness.

\begin{tabular}{llllll}
\hline Material & $\begin{array}{l}\text { Maximum inner } \\
\text { surface }\left({ }^{\circ} \mathrm{C}\right)\end{array}$ & $\begin{array}{l}\text { Minimum inner } \\
\text { surface }\left({ }^{\circ} \mathrm{C}\right)\end{array}$ & Oscillation $\left({ }^{\circ} \mathrm{C}\right)$ & Lag $(\mathrm{h})$ & $\begin{array}{l}\text { Decrement } \\
\text { factor }\end{array}$ \\
\hline Concrete & 36.16 & 23.84 & 12.32 & 4.51 & 0.6172 \\
Brick & 32.94 & 27.06 & 5.88 & 7.35 & 0.2952 \\
Granite & 36.29 & 23.71 & 12.58 & 4.41 & 0.6303 \\
Wood middleweight & 30.91 & 29.09 & 1.82 & 11.47 & 0.0932 \\
Insulation & 34.92 & 25.08 & 9.84 & 5.47 & 0.4927 \\
\hline
\end{tabular}

wall will be closer to the inner layer. With this model, it is also possible to analyse multilayer walls where each layer ( $i$ ) is divided into $n / i$ nodes.

\subsection{Study of the thermal inertia of materials}

Once the model was obtained, the response of different materials to a sinusoidal disturbance with a maximum temperature of $40^{\circ} \mathrm{C}$ and a minimum of $20^{\circ} \mathrm{C}$ was analysed. The results will be obtained taking as a reference a $20 \mathrm{~cm}$ thick wall and 10 nodes will be used for the calculation. This simulation will allow knowing the influence of the properties of the materials (heat capacity, density and conductivity) summarized in Table 1 .

The response obtained when a sine wave perturbs the system is shown in Figure 3. As expected, concrete and granite have a similar behaviour because they show similar thermal properties. These materials have a higher internal temperature oscillation and a smaller lag, showing the worst performance, in spite of their high capacity to accumulate energy. This happens because of their high conductivity, which produces a higher loss of the accumulated heat.

On the other hand, the material that shows the best performance is the wood, despite its not being a material with high energy storage. However, it presents less thermal diffusivity, allowing to retain energy during more time, and therefore, more stable temperatures and a greater time lag. Specifically, the temperature oscillation generated would be $1.82^{\circ} \mathrm{C}$ (compared to $20^{\circ} \mathrm{C}$ external temperature), so it has a factor decrement of 0.0932 (see Tab. 2).

Brick and insulation materials are in the middle. Concerning the insulations, they present high oscillation despite their low thermal diffusivity. Their low capacity of heat accumulation is a disadvantage, so they generate a thermal oscillation of $9.89^{\circ} \mathrm{C}$ and have a smaller lag than 


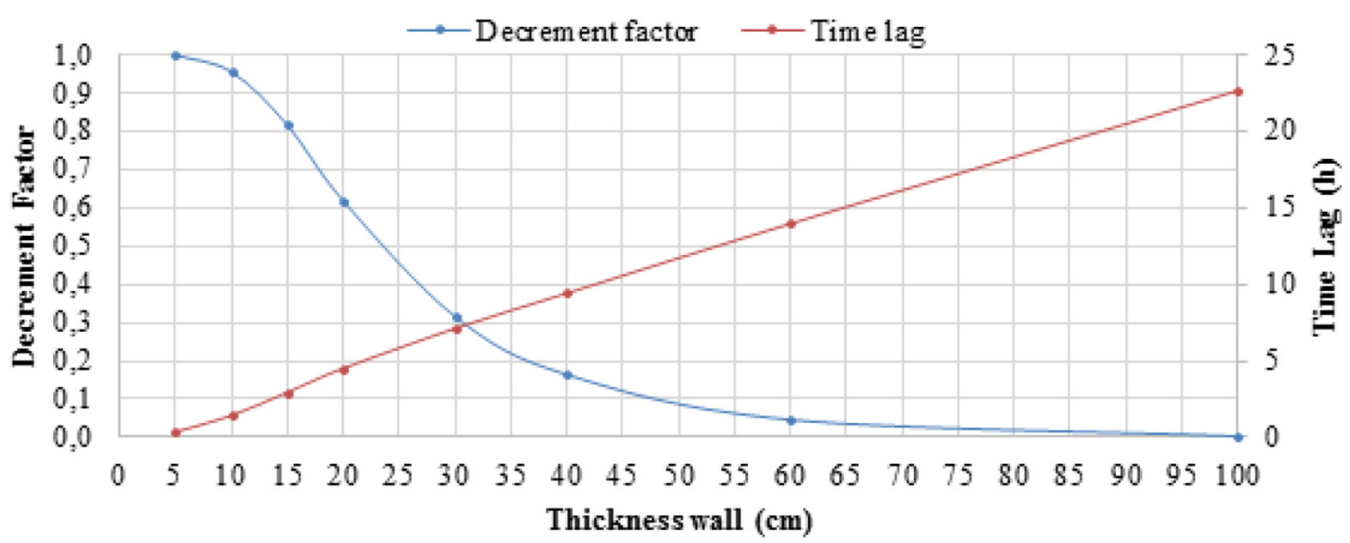

Fig. 4. Representation of decrement factor and time lag according to concrete thickness wall.

Table 3. Summary of layer properties of the wall.

\begin{tabular}{llllll}
\hline Layer & Thickness $(\mathrm{m})$ & $\begin{array}{l}\text { Heat capacity } \\
(\mathrm{J} /(\mathrm{kg} \cdot \mathrm{K}))\end{array}$ & $\begin{array}{l}\text { Density } \\
\left(\mathrm{kg} / \mathrm{m}^{3}\right)\end{array}$ & $\begin{array}{l}\text { Conductivity } \\
(\mathrm{W} /(\mathrm{m} \cdot \mathrm{K}))\end{array}$ & $\begin{array}{l}\text { Thermal resistance } \\
\left(\left(\mathrm{m}^{2} \cdot \mathrm{K}\right) / \mathrm{W}\right)\end{array}$ \\
\hline External air & - & - & - & - & 0.04 \\
Concrete & 0.2 & 1000 & 2400 & 2.5 & 0.08 \\
Insulation & 0.08 & 1404 & 30 & 0.032 & 2.5 \\
\hline
\end{tabular}

Table 4. Summary of the results obtained through the simulation of the two walls.

\begin{tabular}{lllll}
\hline Type of wall & $\begin{array}{l}\text { Thermal mass } \\
\left(\mathrm{J} /\left(\mathrm{m}^{2} \cdot \mathrm{K}\right)\right)\end{array}$ & Oscillation $\left({ }^{\circ} \mathrm{C}\right)$ & Time lag $(\mathrm{h})$ & $\begin{array}{l}\text { Decrement } \\
\text { factor }\end{array}$ \\
\hline Inner insulation and external thermal mass & 483.369 & 7.64 & 7.46 & 0.3199 \\
External insulation and inner thermal mass & 483.369 & 0.26 & 8.01 & 0.0105 \\
\hline
\end{tabular}

wood. Finally, brick generates a better response than insulation. It produces waves with an oscillation of $5.88^{\circ} \mathrm{C}$. Bricks have a factor decrement of 0.2952 and a lag of $7.35 \mathrm{~h}$.

The thickness of the wall also has an important influence on the response of the system, since as the thickness increases, the thermal mass of the system increases. Therefore, to analyze the influence of thickness on the response of the system, the material with the worst performance is taken as a reference, which has been granite and concrete. As can be seen in Figure 4, the decrement factor tends to zero as the wall thickness increases and the time lag increases linearly with the thickness. Therefore, an increase in thickness generates very stable indoor temperatures.

\subsection{Study on the placement of insulation}

The location of thermal insulation in buildings generates a different response in the indoor temperature. To evaluate the influence of the placement of the insulation, the thermal response of two walls composed of $20 \mathrm{~cm}$ of concrete $(2.5 \mathrm{~W} /(\mathrm{m} \cdot \mathrm{K}))$ and $8 \mathrm{~cm}$ thick thermal insulation $(0.032 \mathrm{~W} /(\mathrm{m} \cdot \mathrm{K}))$ will be compared (details shown in Tab. 3). The difference between the two resides in the placement of the insulation, on the one hand, the evolution of the temperature is analysed when the insulation is in the innermost layer and, therefore, the thermal mass is placed in the outer layer. On the other hand, the opposite case is analysed. That is, the insulation is placed on the outer layer and the thermal mass is placed inside the building.

The climate conditions used correspond with a summer day in the city of Ourense (Spain), specifically on July 8th, 2007. This day the maximum temperature was $40.99^{\circ} \mathrm{C}$ at 15:50 hours and the minimum $17.08^{\circ} \mathrm{C}$ [17], producing an oscillation of $23.91^{\circ} \mathrm{C}$.

The enclosure has the same thermal resistance $\left(2.62 \mathrm{~m}^{2} \cdot \mathrm{K} / \mathrm{W}\right)$, and its thermal transmittance has a value of $0.382 \mathrm{~W} /\left(\mathrm{m}^{2} \cdot \mathrm{K}\right)$. Nevertheless, the results obtained are different. The decrement factor and the time lag for each case can be obtained through a simulation in Matlab (results shown in Tab. 4).

When the system is disturbed by a sine wave with an oscillation of $20^{\circ} \mathrm{C}$, the placement of the insulation on the inside generates an oscillation of $7.64{ }^{\circ} \mathrm{C}$ compared to the oscillation of $0.26^{\circ} \mathrm{C}$ that it generates when the insulation is placed on the outside. Introducing the element with greater thermal mass in the outdoor layer (Fig. 5a), energy is stored, but energy is lost more quickly due to its high thermal diffusivity. Therefore there is nothing that 


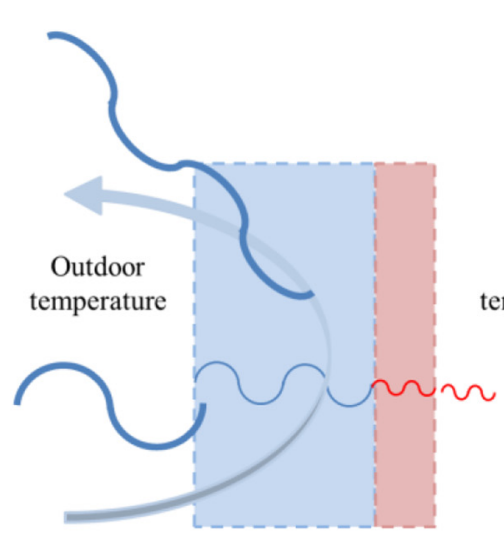

(a)

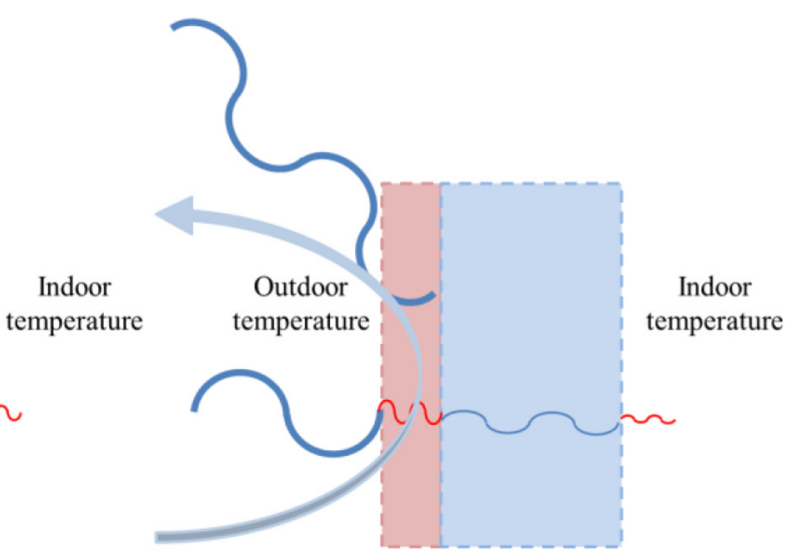

(b)

Fig. 5. Graphical representation of the cushioning effect of the thermal wave which produces each facade. (a) Indoor insulation and outdoor thermal mass. (b) Outdoor insulation and indoor thermal mass.

prevents the leakage of energy to the outside. Moreover, as the insulation has a low thermal diffusivity, it needs more time to accumulate energy, so in the end the energy flowing to the outside is greater than the energy flowing through the insulation.

If insulation is placed outdoor (Fig. 5b), it keeps the inner surface temperature more stable. This stability is produced because the insulation has a lower thermal diffusivity and prevents energy from flowing outside through the concrete. In this way, the innermost wall accumulates a greater amount of energy, returning the heat inside.

The response of the two walls analysed is shown in Figure 6. Depending on the position of the insulation, great differences can be observed. If the insulation is placed in the outside layer and thus the thermal mass is inside, a constant temperature is recorded in the inner surface. Regarding the time lag, the resultant wave is delayed 0.5 hours more than when the insulation is placed inside.

It is interesting to analyse the time response of each wall, that is, the time that the system takes to stabilize itself when it is perturbed by any disturbance. Both systems are subjected to a unitary step disturbance and the results are obtained through a simulation in Matlab. Figure 7 shows when the insulation is inside and when the insulation is placed in the outside layer. In the first case, the response reaches $63 \%$ the perturbation in $0.5 \times 10^{5} \mathrm{~s}$ $(13.9 \mathrm{~h})$ and, in the second case in $1.3 \times 10^{6}$ seconds (15 days). The results obtained between both walls are different, obtaining a greater stability when the thermal mass is placed inside. The thermal mass generates little oscillations in the inner surface temperature and a greater time lag of the thermal wave.

\subsection{Study of the temperature inside a building}

To estimate the indoor temperature, it is necessary to complete the mathematical model. In this case, the electric

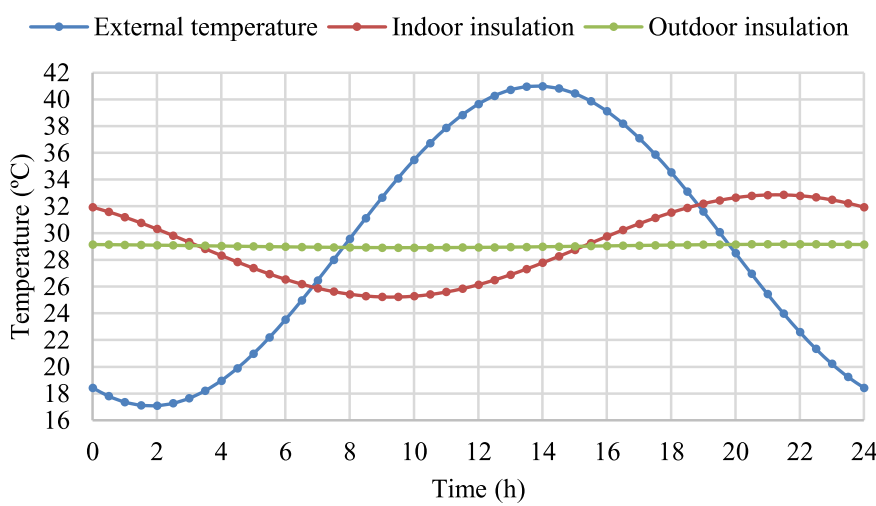

Fig. 6. Variation of inner surface temperature in a wall with outdoor and indoor thermal mass.

analogy is discarded and, therefore, the global energy balance of a building will be used.

When the energy balance of a building is made, the know variables are the external temperature and the inner surface temperature, which is calculated previously by the method of Equivalent Electrical Network. In the energy balance we include the energy exchange of the elements of the envelope with outdoors and with zones at a constant temperature. Air renovations and heat contributions of people or electrical equipment are also included. All these heat inputs are accumulated inside a building by the air. Therefore, the energy balance is shown in equation (9).

$$
\begin{array}{r}
\sum_{\mathrm{I}} \mathrm{h}_{\text {in }} \cdot \mathrm{A}_{i} \cdot\left(\mathrm{T}_{\text {sur,in }}(\mathrm{t})-\mathrm{T}_{\text {in }}(\mathrm{t})\right)+\sum_{\mathrm{i}} \mathrm{h}_{\mathrm{in}} \cdot A_{0, i} \cdot\left(\mathrm{T}_{0, i}(\mathrm{t})-\mathrm{T}_{\mathrm{in}}(\mathrm{t})\right) \\
\quad+0,32 \cdot \mathrm{n} \cdot \mathrm{V} \cdot\left(\mathrm{T}_{\text {ext }}(\mathrm{t})-\mathrm{T}_{\text {in }}(\mathrm{t})\right)+\mathrm{Q}_{\text {in }}(\mathrm{t})=\mathrm{C}_{p, \text { air }} \cdot \frac{\mathrm{dT}_{\mathrm{in}}(\mathrm{t})}{\mathrm{dt}}
\end{array}
$$




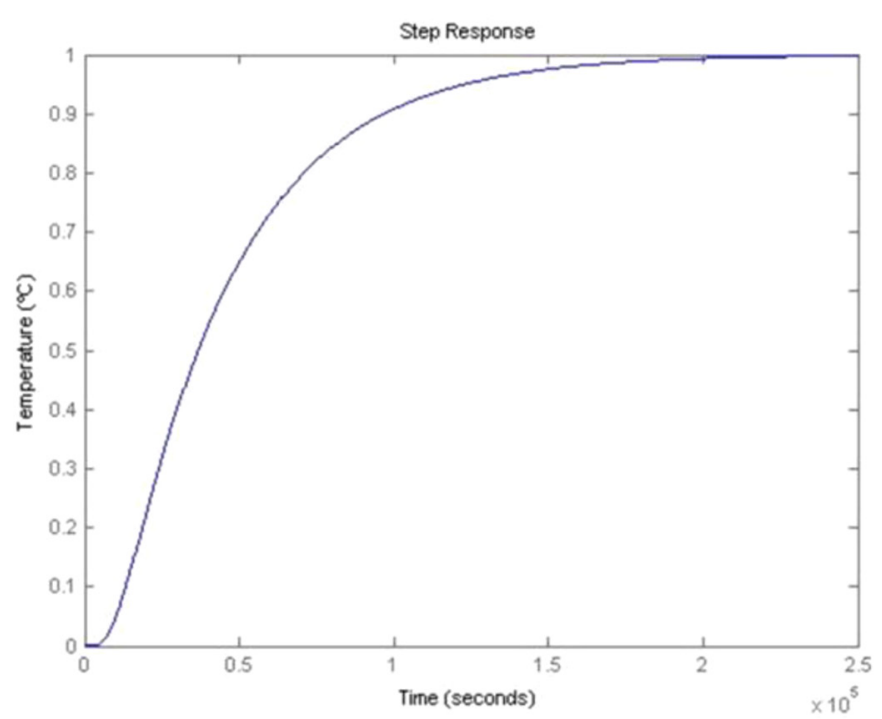

(a)

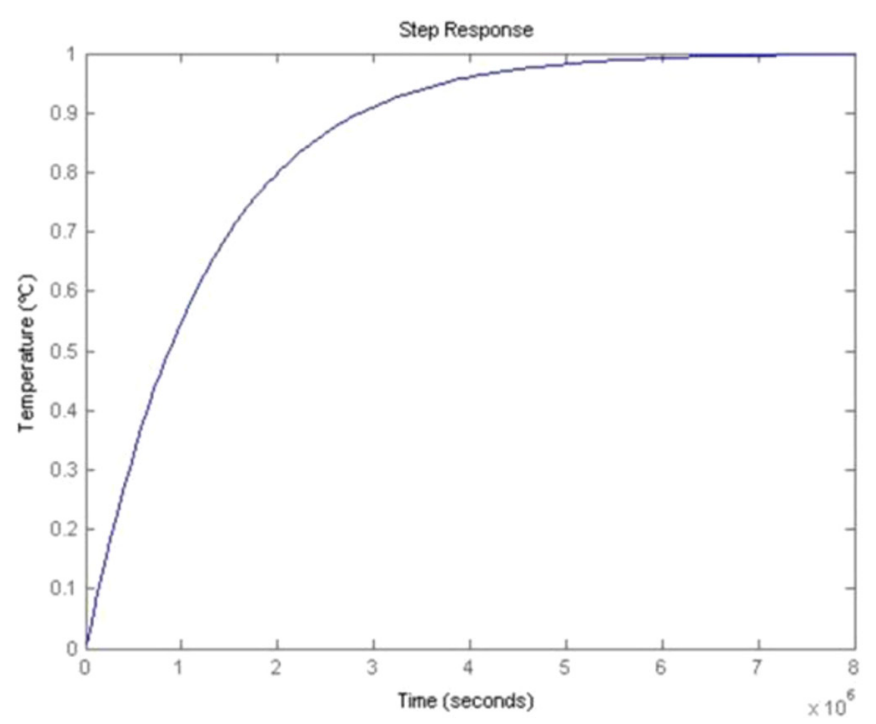

(b)

Fig. 7. System response when it is subjected to a unitary step disturbance (Extracted from Matlab). (a) Inside insulation and outside thermal mass. (b) Outside insulation and inside thermal mass.

where $h_{\text {in }}$ : is the convection coefficient of air inside $\left(7.69 \mathrm{~W} /\left(\mathrm{m}^{2} \cdot \mathrm{K}\right)\right) ; A_{i}$ is the area of inner surface of the envelope elements against outdoors $\left(\mathrm{m}^{2}\right) ; T_{\text {sur.in }}$ : is the inner surface temperature of each envelope element $\left({ }^{\circ} \mathrm{C}\right)$; $T_{\text {in }}$ is the temperature inside a building $\left({ }^{\circ} \mathrm{C}\right) ; A_{0, i}$ is the area of inner surface of each envelope element against a place with constant temperature $\left(\mathrm{m}^{2}\right) ; T_{0, i}$ is the temperature of each zones at constant temperature $\left({ }^{\circ} \mathrm{C}\right) ; n$ is the number of air renovations $\left(\mathrm{h}^{-1}\right) ; V$ is the volume of the building analysed $\left(\mathrm{m}^{3}\right) ; T_{\text {ext }}$ is the external temperature $\left({ }^{\circ} \mathrm{C}\right) ; Q_{\text {in }}$ is the internal loads produced by electronic equipment and by the people living in the building $\left(\mathrm{W} / \mathrm{m}^{2}\right) ; C_{p \text {,air }}$ : is the heat capacity of the air $(\mathrm{J} / \mathrm{K})$.

The transfer function to estimate the temperature inside a building is obtained based on the system disturbances. For this, it is necessary to solve equation (9) using the Laplace transformation. This gives as a result equation (10).

\section{See equation (10) below.}

By equation (10), the indoor temperature can be calculated in Laplace domain based on their input variables. The equation is solved by Matlab, which allows us to obtain the temperature evolution in the time domain.
With the purpose of analysing a real case, a standard building is taken as a reference. To simplify the operations, the building will be considered as a block. The dwelling has a surface of $80 \mathrm{~m}^{2}$. Two of its facades and its roof are in contact with outdoors, while its other two walls and the concrete deck are in contact with a zone having a constant temperature. These last elements are composed of concrete with a $20 \mathrm{~cm}$ thickness.

The elements in contact with outdoors, including the flat roof, are composed of $20 \mathrm{~cm}$ of concrete and $8 \mathrm{~cm}$ of insulation. This type of elements are analysed from two points of view. Firstly, the thermal mass is placed outside and the insulation in the innermost layer. Secondly, the insulation is placed outside and, therefore, the thermal mass is inside. The thermal properties of the materials are shown in Table 3 and the responses of each facade are in Table 4.

As a reference, the climatic conditions that have been used to the simulation correspond to one of the coldest days recorded in the city of Ourense (the 5th of February 2012). The maximum temperature reached was $8.89^{\circ} \mathrm{C}$ and the minimum temperature was $-5.85^{\circ} \mathrm{C}$ [17].

Figure 8 shows the temperature evolution inside a building when the insulation is inside and outside, disregarding the internal loads and the solar radiation. When insulation is inside, the system response is a sine

$$
\begin{aligned}
\mathrm{T}_{\mathrm{int}}(\mathrm{s})= & \sum_{i} \frac{\mathrm{h}_{\mathrm{int}} \cdot \mathrm{A}_{i}}{\mathrm{~h}_{\mathrm{int}} \cdot \sum\left(\mathrm{A}_{i}+\mathrm{A}_{0, i}\right)+0,32 \cdot \mathrm{n} \cdot \mathrm{V}+\mathrm{C}_{p, \text { air }} \cdot \mathrm{s}} \cdot \mathrm{T}_{\text {sup }, \mathrm{i}}(\mathrm{s})+\sum_{i} \frac{\mathrm{h}_{\text {int }} \cdot \mathrm{A}_{0}}{\mathrm{~h}_{\mathrm{int}} \cdot \sum\left(\mathrm{A}_{i}+\mathrm{A}_{0, i}\right)+0,32 \cdot \mathrm{n} \cdot \mathrm{V}+\mathrm{C}_{p, \text { aire }} \cdot \mathrm{s}} \cdot \mathrm{T}_{0, i}(\mathrm{~s}) \\
& +\frac{0,32 \cdot \mathrm{n} \cdot \mathrm{V}}{\mathrm{h}_{\mathrm{int}} \cdot \sum\left(\mathrm{A}_{i}+\mathrm{A}_{0, i}\right)+0,32 \cdot \mathrm{n} \cdot \mathrm{V}+\mathrm{C}_{p, \text { aire }} \cdot \mathrm{s}} \cdot \mathrm{T}_{\text {ext }}(\mathrm{s})+\frac{1}{\mathrm{~h}_{\mathrm{int}} \cdot \sum\left(\mathrm{A}_{i}+\mathrm{A}_{0, i}\right)+0,32 \cdot \mathrm{n} \cdot \mathrm{V}+\mathrm{C}_{p, \text { aire }} \cdot \mathrm{s}} \cdot \mathrm{Q}_{\mathrm{in}}(\mathrm{s})
\end{aligned}
$$




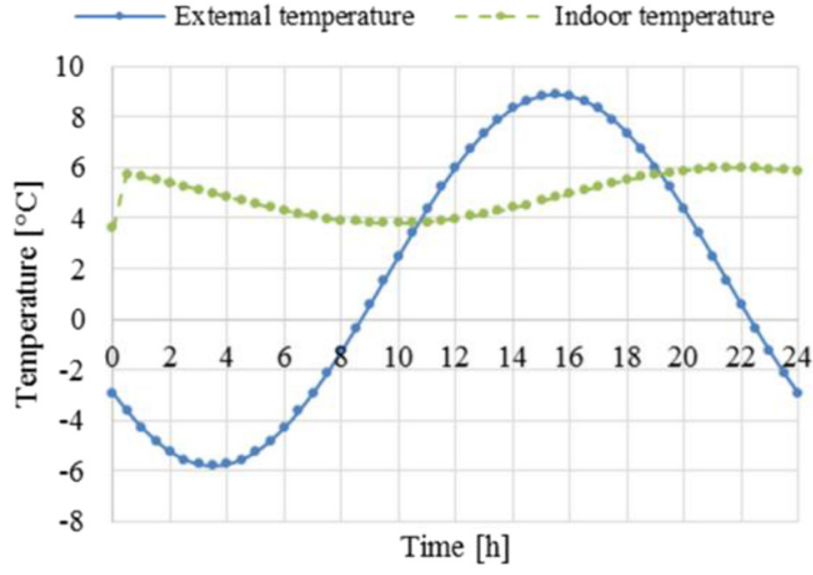

(a)

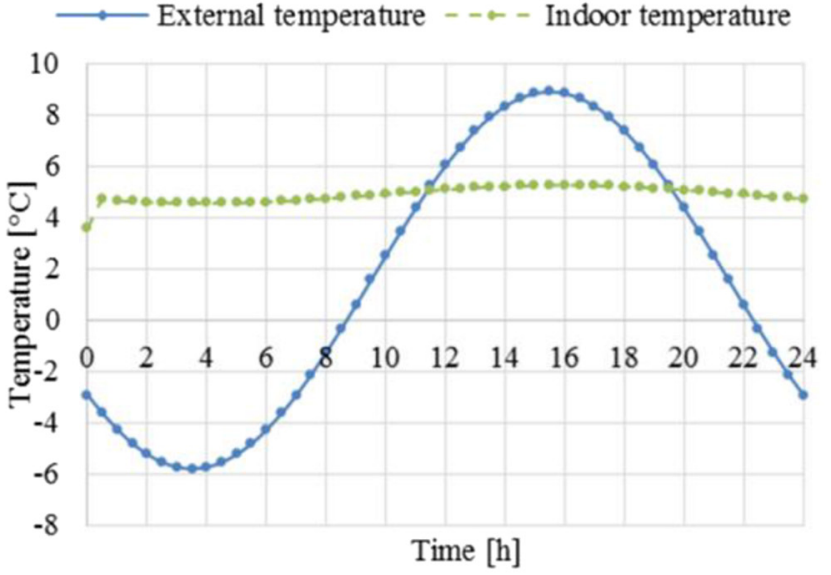

(b)

Fig. 8. Variation of indoor temperature depending on the placement of the insulation. (a) Inside insulation and outside thermal mass. (b) Outside insulation and inside thermal mass.

wave with less amplitude and with a different phase. Specifically, a maximum temperature of $6.0^{\circ} \mathrm{C}$ and a minimum of $3.8^{\circ} \mathrm{C}$, so the average temperature is $4.90^{\circ} \mathrm{C}$, with a time lag of 6.5 hours. The average temperature is greater than the outdoor, as the building is in contact with zones with a constant temperature, which is higher than the outdoor average, increasing the inner average temperature.

When the thermal mass is in the innermost layer, the temperature variation of the building is practically constant, reaching a maximum of $5.25^{\circ} \mathrm{C}$ and a minimum of $4.55^{\circ} \mathrm{C}$. As for the time lag, the resultant wave is in the same phase than the disturbance. This is due to the influence of the air renovations. As in the inner surface, the temperature is nearly constant. This parameter is influenced by the energy flow of the air renovations, which is a wave with the same phase than external temperature. This produces that the time lag of resultant wave is lost.

If both results are compared, we can observe that the temperature is more stable when the thermal mass is inside and the insulation is placed outdoors. The temperature variation obtained is $0.70^{\circ} \mathrm{C}$ versus $2.2^{\circ} \mathrm{C}$, obtained when the thermal mass is outdoors.

\subsection{Study of the influence of solar radiation through walls}

For studying the solar radiation through a wall, sol-air temperature will be included in the model. The sol-air temperature is the outdoor temperature, which in absence of all radiation exchanges, generates the same heat flow through a wall that is equal to the combination of the solar incident radiation, the exchange of radiant energy with the sky and the exchange of heat convection with outdoor air [18].

$$
\mathrm{T}_{\text {sol-air }}=\mathrm{T}_{\text {ext }}+\frac{\alpha_{0} \cdot \mathrm{G}_{t}}{\mathrm{~h}_{0}}-\frac{\varepsilon \cdot \Delta \mathrm{R}}{\mathrm{h}_{0}}
$$

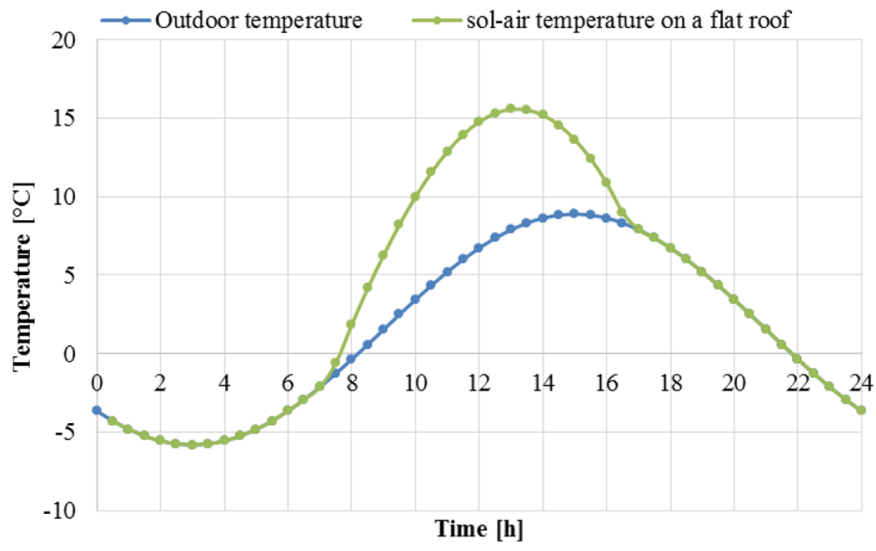

Fig. 9. Graphical representation of the outdoor temperature and the sol-air temperature on a horizontal surface.

Therefore, sol-air temperature allows knowing the amount of heat conduction through the wall from the outside including solar radiation.

Vertical surfaces receive long-wave radiation from the ground, the sky and from other vertical surfaces, so determine the value of $\Delta R$ with precision is complex. When solar radiation is high, the temperature of objects are higher than air temperature, thus, the long wave radiation compensates the low emittance of the sky. Therefore, we can assume in vertical surfaces that $\varepsilon \cdot \Delta R=0$. On the other hand, for horizontal surfaces, the long wave radiation is only received from the sky, so the term $\Delta \mathrm{R}$ has a value of $20 \mathrm{BTU} / \mathrm{h} \cdot \mathrm{ft}^{2}\left(63.09 \mathrm{~W} / \mathrm{m}^{2}\right)[18]$.

Sol-air temperature will be included in the model. The influence of solar radiation on the outside surface of the wall makes that heat flow that occurs will be equivalent to a maximum temperature of $16.14^{\circ} \mathrm{C}$. The sol-air temperature must be calculated for every enclosure because the value depends on its tilt and orientation. In the Figure 9, the sol-air temperature for a horizontal surface $(\beta=0, \gamma=0)$ is showed: 

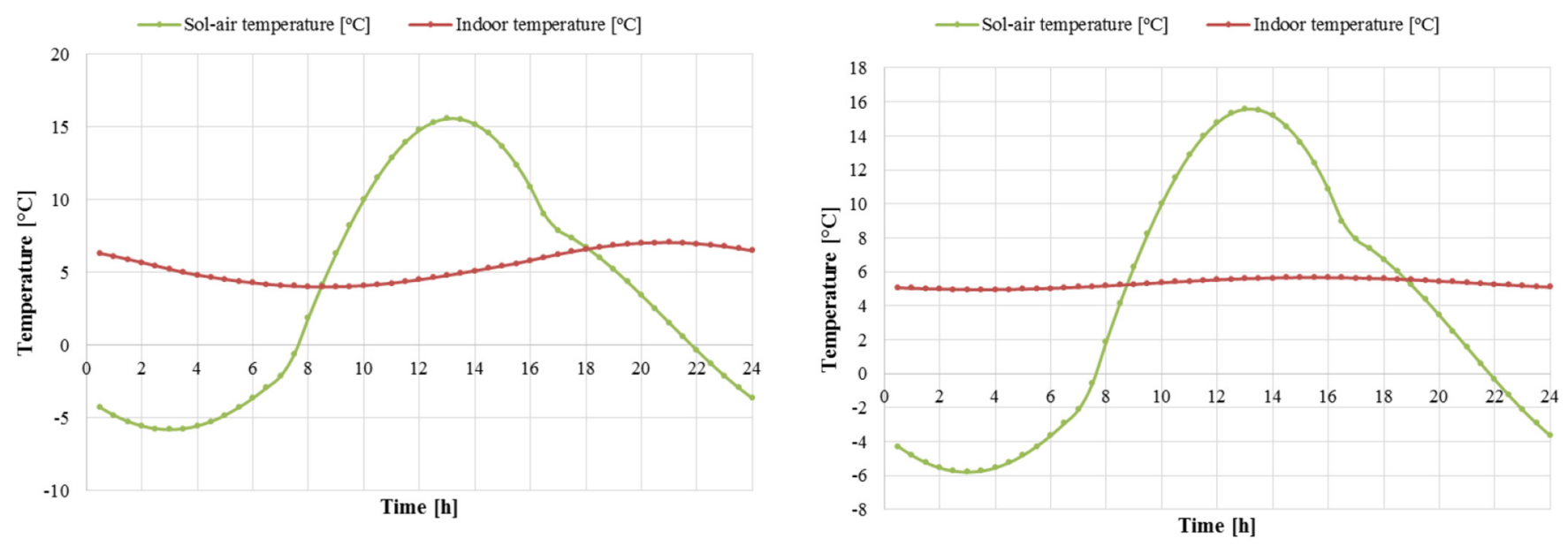

Fig. 10. Variation of the indoor temperature for walls taking into account the solar radiation. On the left with inside insulation. On the right with outside insulation.

Figure 10 shows the influence of solar radiation through the walls. In this case, the indoor temperature increases in $0.5^{\circ} \mathrm{C}$, therefore, the average temperature in a building is increased and it reaches $5.5^{\circ} \mathrm{C}$. However, the oscillation is higher when the insulation is inside and the total oscillation reaches the $2.6^{\circ} \mathrm{C}$. On the other hand, when the insulation is outside a constant response is produced. So when solar radiation is introduced is not appreciated an increase of temperature. The maximum temperature reached is $5.66^{\circ} \mathrm{C}$ and the minimum is $4.95^{\circ} \mathrm{C}$ so the average temperature is $5.30^{\circ} \mathrm{C}$. The average temperature is lower than with the inside insulation because this configuration is less influenced by solar radiation. However, temperatures more stables are achieved with the outside insulation.

\subsection{Study of the influence of solar radiation through windows}

The main solar contributions in a building are produced through the windows. Therefore, it is interesting to analyse the influence of this energy in the indoor temperature. These contributions of energy can increase the indoor temperature in winter, however, they can produce an excess of temperature in summer so it is necessary look for a balance between this two situations.

The first step to study the influence of solar radiation is to add the solar radiation through windows to equation (10) and solve it using Laplace transformation.

See equation (12) below.
This new term $\left(Q_{\text {solar }}\right)$ depends on the orientation, the tilt and the properties of windows. So, solar contributions are equal to the direct solar radiation multiplied by the solar factor of the glass. The solar factor of the window is the relationship between total energy which enters the room through the glass and the incident solar energy. This total energy is the sum of solar energy that enters through direct transmission and energy transferred from the glazing to the indoor space.

To analyse the influence of solar radiation, we will use a glazed surface of $12 \mathrm{~m}^{2}$ (20\% of the surface of the facade). The window has double glazing with a transmittance of $3.1 \mathrm{~W} / \mathrm{m}^{2} \mathrm{~K}$ and a solar factor of 0.75 .

Figure 11 shows the evolution during the winter of the indoor temperature taken into account the solar radiation. With the inside insulation, an internal temperature of $8.04^{\circ} \mathrm{C}$ is reached, while when placing the insulation on the outside, the temperature reached is $8.37^{\circ} \mathrm{C}$. This difference is produced by the time lag of each wave. When insulation is on the outside and therefore the thermal mass is inside, the indoor temperature is more stable, and the solar radiation increases the indoor temperature during the hours with more sunshine. However, when the insulation is in the outside, the wave lag produces a maximum.

\section{Discussion}

The model described in this paper using the electrical analogy, allows predicting the thermal behaviour of the enclosures in a simple way, without the need for complex

$$
\begin{aligned}
T_{\text {int }}(s)= & \sum_{i} \frac{h_{\text {int }} \cdot A_{i}}{h_{\text {int }} \cdot \sum\left(A_{i}+A_{0, i}\right)+0,32 \cdot n \cdot V+C_{p, \text { aire }} \cdot s} \cdot T_{\text {sup }, i}(s)+\sum_{i} \frac{h_{\text {int }} \cdot A_{0}}{h_{\text {int }} \cdot \sum\left(A_{i}+A_{0, i}\right)+0,32 \cdot n \cdot V+C_{p, \text { aire }} \cdot s} \cdot T_{0, i}(s) \\
& +\frac{0,32 \cdot n \cdot V}{h_{\text {int }} \cdot \sum\left(A_{i}+A_{0, i}\right)+0,32 \cdot n \cdot V+C_{p, \text { aire }} \cdot s} \cdot T_{\text {ext }}(s)+\frac{1}{h_{\text {int }} \cdot \sum\left(A_{i}+A_{0, i}\right)+0,32 \cdot n \cdot V+C_{p, \text { aire }} \cdot s} \\
& \cdot Q_{\text {internas }}(s)+\frac{1}{h_{\text {int }} \cdot \sum\left(A_{i}+A_{0, i}\right)+0,32 \cdot n \cdot V+C_{p, \text { aire }} \cdot s} \cdot Q_{\text {solar }}(s)
\end{aligned}
$$




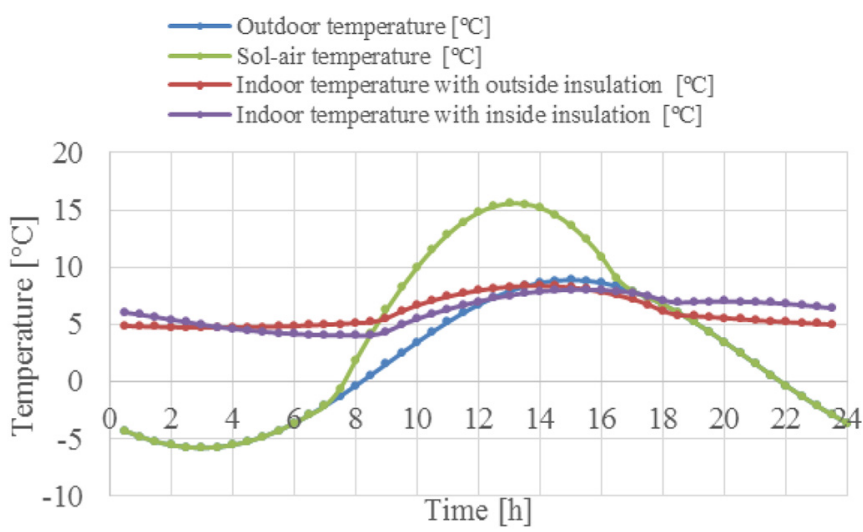

Fig. 11. Variation of the indoor temperature for walls with inside and outside insulation and taking into account the solar radiation through the window during a winter day.

simulations. The selection of the suitable materials, allows optimizing the thermal behaviour of the buildings and therefore they must be selected properly. The materials that generate a softer internal temperature and greater time lag are those with higher density and low thermal conductivity, due to the high capacity to accumulate heat.

Among the materials used, wood is the one with the best thermal behaviour, generating a more stable temperature inside and producing a time lag of $11.47 \mathrm{~h}$. Wood is a material with great potential, since its use as a substitute for conventional construction materials can reduce $\mathrm{CO}_{2}$ emissions by $69 \%$ in the construction phase [19]. In the second place is the brick with a decrement factor of 0.2952 and a time lag of $7.35 \mathrm{~h}$.

Granite and concrete are materials with similar properties and therefore a similar response is obtained. These types of materials, despite not having the best thermal response, are widely used materials in old buildings. In this type of construction, the materials generate a lower temperature oscillation and a greater time lag.

The placement of thermal insulation is an important point to take into account when designing a building. In this case, a comparison was made with respect to placing the insulation inside or outside. The results show that placing the insulation on the outside generates more stable temperatures, with a temperature oscillation of $0.26{ }^{\circ} \mathrm{C}$ compared to $7.64^{\circ} \mathrm{C}$ when placing the insulation inside. In addition, by analysing a variation in the outside temperature over a longer period of time, placing the insulation outside allows to obtain a system that is more stable to changes. The use of insulation inside the walls eliminates the thermal capacity of heat accumulation, generating a greater fluctuation in temperature.

Introducing solar radiation into the model allows an accurate estimation of the indoor temperature of buildings. Solar radiation through the walls of the building causes different disturbances in the indoor temperature depending on the location of the insulation. By introducing solar radiation into the model, there is an increase in temperature inside due to the heat that enters the building by conduction. During winter, a maximum temperature of $7^{\circ} \mathrm{C}$ is produced when the insulation is inside, while when the insulation is placed outside, the maximum temperature reached is $5.66^{\circ} \mathrm{C}$.

The inputs of solar radiation through the windows, causes a greater change in the indoor temperature. In the case analysed, a low-quality window is used, in order to observe the influence of solar radiation on the indoor temperature. In this way, it is observed that during the winter, the entry of solar radiation causes a greater oscillation when the thermal mass is placed inside $\left(T_{\max }=8.37^{\circ} \mathrm{C}\right)$ compared to when the thermal mass is outside $\left(T_{\max }=8.04^{\circ} \mathrm{C}\right)$.

In summer solar inputs can generate uncomfortable indoor temperature, so the use of solar shadow devices would control the overheating generated by solar radiation.

\section{Conclusions}

In this paper, a mathematical model has been developed, which allows for obtaining the temperature variation inside a building, using the analogy between electric field and thermal field and, an energy balance. The results obtained show the following:

- The materials with better behaviour, when are perturbed by a sine disturbance, have a high density and heat capacity and a low thermal conductivity.

- The thickness of the wall is important to obtain more stable indoor conditions. When the thickness increases, the thermal mass also increases. Thus, when the thickness is high, the factor decrement can be nearly zero. - Introducing thermal mass inside and insulation outside generates more stable temperatures than placing insulation inside, in spite of the thermal transmittance having the same value in both cases.

- Placing the thermal mass inside produces a lower heat flow than when it is placed outside. This option allows designing climate systems with less power.

- When the building's behaviour is simulated, the indoor temperature is more stable when the thermal mass is inside. However, the influence of the loss of energy, due to air renovations, causes that indoor temperature was practically in the same phase than external temperature.

- Solar radiation through the enclosures does not generate large fluctuations in temperature. However, placing the insulation on the inside generates a higher indoor temperature during winter.

- Solar contributions through the window generate a greater impact on the indoor temperature with respect to the heat flow through the enclosure.

The design of thermal envelope is basic to achieve nearly Zero-Energy Buildings. However, achieving enclosures with a low thermal transmittance is not enough. The order of the wall components is also important, systems with the thermal mass inside and the insulation outside showing more advantages.

Being able to predict the temperature inside a building is useful in the design of air conditioning control systems. An approximation of the outside temperature evolution 
can be obtained from the weather forecast. Thus, it can be designed a control system which anticipates to outside temperature variations, in order to keep the indoor temperature in comfort zone.

\section{References}

1. IPCC, Climate Change 2014: Synthesis Report, 2014

2. $\mathrm{EC}, \mathrm{COM}(2008) 772$, Communication from the Commission of 13 November 2008. Energy efficiency: delivering the $20 \%$ target. Brussels, 2008

3. EU Directive 2018/844 of the European Parliament and of the Council of 30 May 2018 amending Directive 2010/31/EU on the energy performance of buildings and Directive 2012/ $27 /$ EU on energy efficiency

4. European Environment Agency: https://www.eea.europa.eu/ [Accessed March 2021]

5. S. Ferrari, in 28th AIVC and 2nd Palenc Conference: Building Low Energy Cooling and Ventilation Technologies in the 21st Century, 2007

6. T. Ihara, A. Gustavsen, B. Petter Jelle, Appl. Energy 158 (2015)

7. E. Kosseckaa, J. Kosnyb, Energy Build. 34, 4 (2002)
8. N. Aste, A. Angelotti, M. Buzzetti, Michela. Energy Build. 41, 11 (2009)

9. C. Avendaño-Vera, A. Martinez-Soto, V. Marincioni, Renew. Sustain. Energy Rev. 131 (2020)

10. K.J. Kontoleon, Th.G. Theodosiou, K.G. Tsikaloudaki, Appl. Energy 112 (2013)

11. S. Martín, F.R. Mazarrón, I. Cañas, Construct. Build. Mater. 24, 5 (2010)

12. G. Evola, L. Marletta, S. Natarajan, E.M. Patanè, Energy Proc. 133 (2017)

13. S.A. Al-Sanea, M.F. Zedan, S.N. Al-Hussain, Appl. Energy 89, 1 (2012)

14. E. Stéphan, R. Cantin, A. Caucheteux, S. Tasca-Guernouti, P. Michel, Build. Environ. 80 (2014)

15. S. Verbeke, A. Audenaert, Renew. Sustain. Energy Rev. 82, 3 (2018)

16. N. Aste, F. Leonforte, M. Manfren, M. Mazzon, Appl Energy 145 (2015)

17. Meteogalicia: https://www.meteogalicia.gal/web/inicio.action

18. American Society of Heating, Refrigerating and Air-Conditioning Engineers, Inc. HVAC Applications, edited by ASHRAE, SI Edition (Atlanta 2011)

19. A. Himes, G. Busby, Dev. Built Environ. 4 (2020)

Cite this article as: Andrés Vilaboa Díaz, Pastora M. Bello Bugallo, Development and Application of a Thermal Comfort Model in Buildings, Renew. Energy Environ. Sustain. 7, 1 (2022) 